\title{
Ohvira syndrome with left radial hemimelia: a rare association
}

\author{
Jayanthy T.*, Rachana B. Rao
}

Department of Obstetrics and Gynaecology, Kempegowda Institute of Medical Sciences, Bangalore, Karnataka, India

Received: 28 June 2021

Revised: 07 July 2021

Accepted: 29 July 2021

\section{*Correspondence:}

Dr. Rachana B. Rao,

E-mail: rachanabrao@gmail.com

Copyright: (c) the author(s), publisher and licensee Medip Academy. This is an open-access article distributed under the terms of the Creative Commons Attribution Non-Commercial License, which permits unrestricted non-commercial use, distribution, and reproduction in any medium, provided the original work is properly cited.

\begin{abstract}
Ohvira syndrome is rare complex anomaly consisting of uterus didelphys, unilateral ipsilateral obstructed hemivagina and ipsilateral renal agenesis. It typically presents with dysmenorrhea or pelvic pain shortly after menarche due to collection of secretions in the uterus. Reporting a case of 32 years unmarried nulligravida lady with complaints of pain abdomen since 20 days with history of similar complaints 15 years bac. Patient was on Inj. DMPA 2 years back. On examination upper limb skeletal deformity-left radial hemimelia present with a mass of 14-16 weeks gravid uterus on per abdomen examination. USG (February 2020), was suggestive of uterus didelphys bicollis with collection of 108 cc noted in the right uterine cavity with right kidney agenesis with obscured right ovary. Total abdominal hysterectomy with left salphingo-oopherectomy was done. Specimen features were suggestive of uterus didelphys bicornis bicollis with right uterus hematometra with right cervix blind with right sided blind vagina with features suggestive of Ohvira syndrome.
\end{abstract}

Keywords: Haematometra, Hemimelia, Ohvira syndrome

\section{INTRODUCTION}

Ohvira syndrome Is a rare complex anomaly with obstructed hemivagina with ipsilateral renal agenesis. Incidence is 0.1 to $3.8 \% .^{1}$ There is no reported case of ohvira syndrome with Left Radial Hemimelia. It typically presents with dysmenorrhea or pelvic pain shortly after menarche due to collection of secretions in the uterus.

\section{CASE REPORT}

A 32-year-old unmarried nulligravida lady with left upper limb deformity came with complains of sided pain abdomen since 20 days. In view of difficulty and painful micturition and difficulty in defecation with scanty menstruation, patient underwent laparoscopic surgery and findings were bicornuate uterus with right sided hematocolpos with haemosalphinx with right adnexal mass 14 years back. 2years back patient was admitted, diagnosed with PID and treated for the same. She was started on inj DMPA once every 3 months in view of severe dysmenorrhoea 2 years back.

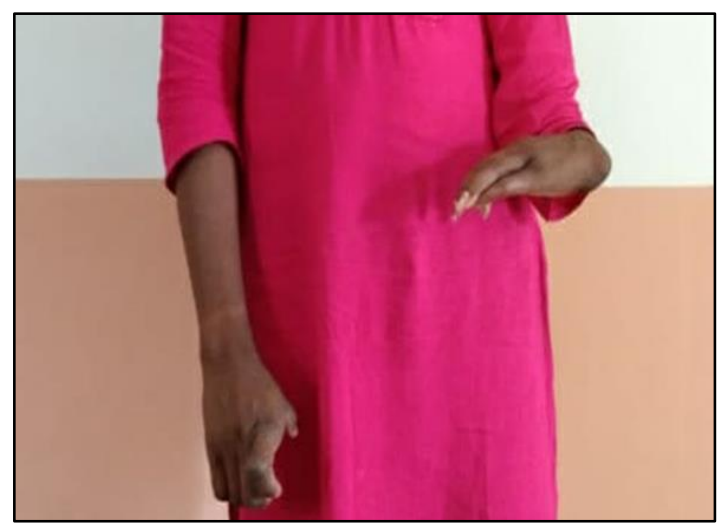

Figure 1: Left radial hemimelia.

Age of Menarche - 12 years. Patient had regular cycles, 12 days flow every 28- 30 days, not associated with clots, 
associated with mild dysmenorrhea Scanty flow, changed 1pad per day. LMP: 25/2/2018

Patient gave history of pulmonary tuberculosis, treatment taken 2 years back. No other medical comorbidities. No history of any blood transfusions. No similar complaints/anomalies seen in family members.

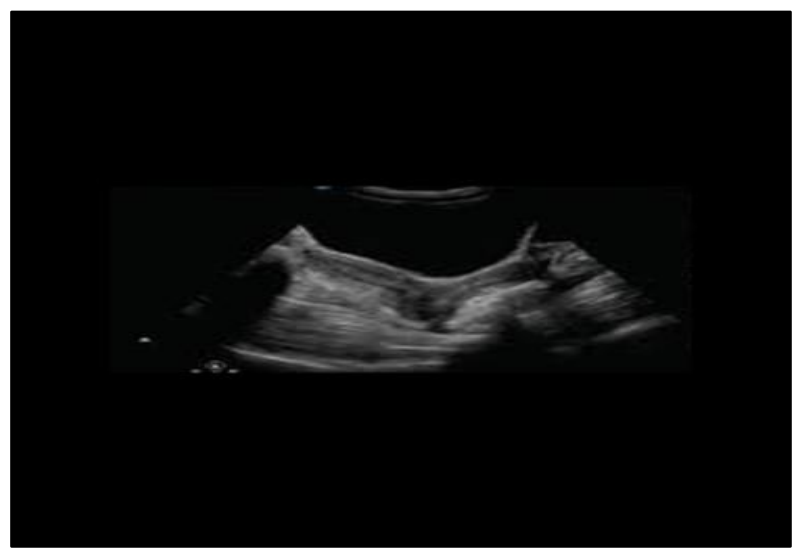

Figure 2: USG pelvis showing uterus Didelphys bicollis.

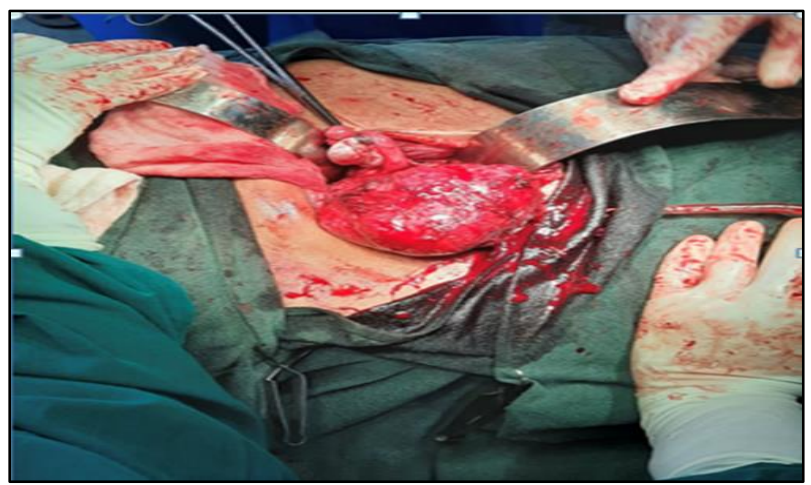

Figure 3: Intraoperative finding.

On examination patient was moderately built and nourished. BMI: $22 \mathrm{~kg} / \mathrm{sq} . \mathrm{m}$ and normal vitals. Pallor was present. Left upper limb multiple deformity - left hemimelia present.

Breast, thyroid and spine clinically appeared normal. RS, CVS and CNS examination were normal. On per abdomen examination, a mass of size equivalent to 14-16 weeks gravid uterus, cystic to firm in consistency, tender, with restricted mobility was felt in the suprapubic region extending to right iliac fossa. On Local examination, external genitalia normal. On Per speculum, cervix normal. Per-vaginal examination showed uterus, 14-16 weeks size, restricted mobility right fornix cystic mass felt, left fornix free, non- tender. Per rectal: Cystic mass in right side of pelvis, non-tender.

All relevant investigations were normal. USG (June 2006) was report was suggestive of Uterus didelphys Uterine cavity, cervix, upper vagina and tube of right horn were distended with turbid fluid suggestive of right sided hematometrocolpos with hematosalphinx. Left horn normal. Both ovaries normal. Right kidney not visualised -? absent? ectopic and USG (February 2020) showed two uterine cavity and cervix noted suggestive of uterus didelphys bicollis with rudimentary left horn. Right uterine cavity bulky with ET $-20 \mathrm{~mm}$. Collection noted in right uterine cavity with thick internal echoes and peripheral vascularity $(108 \mathrm{cc})$. Left horn thin endometrium. Collection in cervical canal with ballooning of cervix. Left ovary normal. Right ovary obscured. Hydrosalphinx noted. Small right subserosal fibroid of $2 \times 2 \mathrm{~cm}$. Right kidney agenesis.

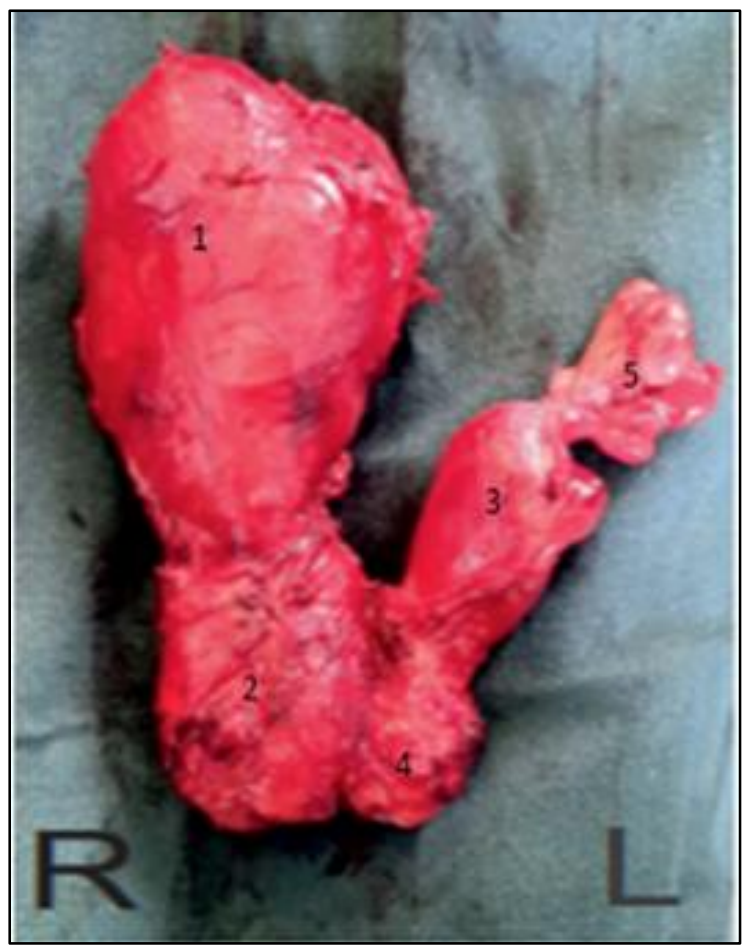

Figure 4: Gross image. (A) Right enlarged uterus. (B) Right blind cervix. (C) Left normal uterus. (D) Left patent cervix. (E) Tubo-ovarian complex.

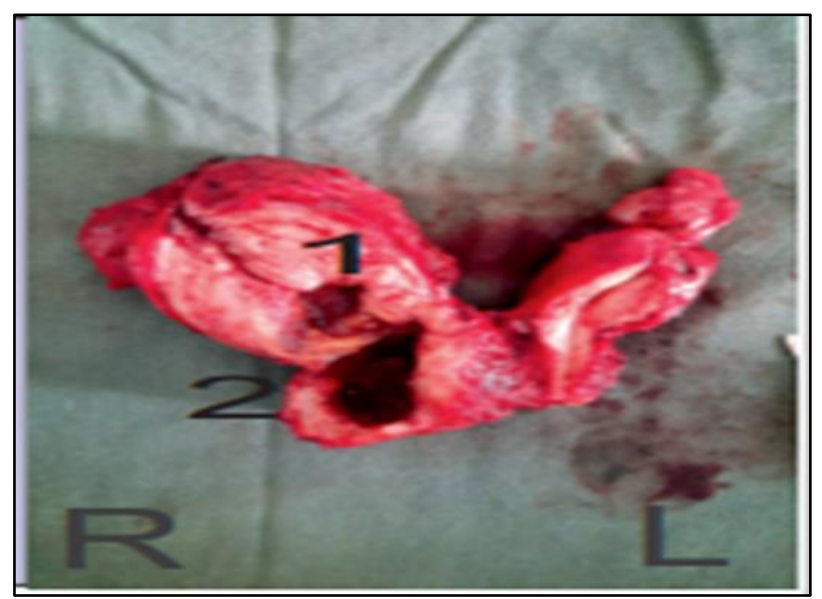

Figure 5: (A) Blind cervix. (B) Blind vagina. 


\section{Treatment}

Patient was counselled and posted for laparotomy and procedure. Intraoperative findings were thick adhesions between Right uterus and bowel. Uterus enlarged. Right tube and ovary adherent. Left uterus normal size, adhesions to bowel and omentum present. Left tube and ovary matted, adherent to uterine fundus, left ovary unhealthy and cystic. Adhesions were released and Total Abdominal Hysterectomy with left salpingooopherectomy done.

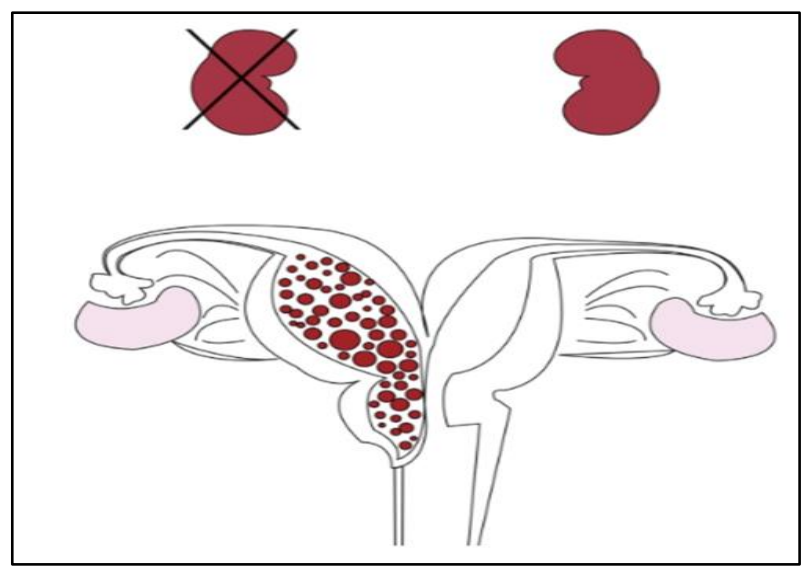

Figure 6: Ohvira syndrome.

\section{Gross}

Right enlarged uterus. Right blind cervix. Left normal uterus. Left patent cervix. Tubo-ovarian complex.

\section{Cut section}

Left uterus - normal. Right uterus thickened. Right cervical canal - blind. Right vagina- blind.

\section{Histopathology report}

Uterus didelphys. Right uterus leiomyomata. Bilateral chronic cervicitis.

Post- operative period uneventful, suture removal done on day 7 and patient discharged under stable condition.

\section{Surgical diagnosis}

Uterus didelphys bicollis with right uterus hematometra with scan showing right kidney agenesis. Suggestive of ohvira syndrome - herlyn - werner - wunderlich syndrome.

\section{DISCUSSION}

Incidence reported is $0.1-3.8 \%$. It was first report in the year 1922. ${ }^{1}$

Common on right side and Common presentation in age group 10-33 years. $^{2,3}$
Familial occurrence has been reported. Genetic predisposition has not yet been identified. It is characterised by congenital birth defect of lower abdominal and pelvic organs.

It is a type of mullerian duct anomaly, consisting of uterus didelphys bicollis, obstructed hemivagina and ipsilateral renal anomaly. ESHRE Classification is U3b C3 V2. ${ }^{4}$

Renal agenesis is due to the developmental arrest in one wollfian duct which in turn affects nephrogenesis and positioning of ipsilateral Müllerian ducts at 8 th week of gestation. $^{5}$

Renal anomalies include agenesis, dysplasia, doubling, ectopic ureter. This malpositioned Müllerian ducts are incapable of fusion leading to two hemiuteri. ${ }^{6}$

Can also be associated with high riding aortic bifurcation, IVC duplication, intestinal malrotation, ovarian malposition. ${ }^{7}$

Typically presents in adolescence with abdominal pain and dysmenorrhea due to obstructed hemivagina, imperforate hymen with or without transverse/longitudinal vaginal septum. $^{8}$

Complications include Retrograde menstruation, secondary infections, adhesions, PID, infertility, complicated pregnancy, labour endometriosis. ${ }^{9}$ Diagnosis is by Ultrasound as it is useful in detecting haematocolpos and hematometra and uterine and renal anomalies. MRI is considered gold standard. ${ }^{10}$

Treatment has been tailored according to needs of the patient. Resection of vaginal septum to relieve obstruction. This improves sexual function and reduces risks of retrograde menstruation but in cases where severe adhesions, endometriosis and hematometra and severely damaged tubes, conservative surgery may not be possible and hysterectomy have to be considered.

\section{CONCLUSION}

Ohvira syndrome is a rare anomaly with potential short term and long-term complications. The diagnosis is likely to be missed due to normal menstruation and non-specific abdominal pain. These cases increase awareness and help in reducing potential consequences.

Funding: No funding sources

Conflict of interest: None declared

Ethical approval: Not required

\section{REFERENCES}

1. Purslow CE. A case of unilateral haematocolpos, haematometra and have metosalpinx $\mathbf{J}$ obstetric Gynaecol Br Emp. 1922;29:643. 
2. Tong J, Zhu L, Lang J. Clinical characteristics of 70 patients with Herlyn-Werner-Wunderlich syndrome. Inter J Gynecol Obstet. 2013;121(2):173-5.

3. Ugurlucan F, Dural O, Yasa C, Kirpinar G, Akhan S. Diagnosis, management, and outcome of obstructed hemivagina and ipsilateral renal agenesis (OHVIRA syndrome): Is there a correlation between MRI findings and outcome. Clin Imag. 2020;59(2):172-8.

4. Mandava A, Prabhakar RR, Smitha S. OHVIRA syndrome (obstructed hemivagina and ipsilateral renal anomaly) with uterus didelphys, an unusual presentation. J Pediatr Adolesc Gynecol. 2012;25:e23-5.

5. Kimble RM, Khoi SK, Baartz D, Kimble RM. The obstructed hemivagina, ipsilateral renal anomaly, uterus didelphys triad. Aust N Z J Obstetric Gynaecol. 2009;49:554-7.

6. El-Gohary MA. Uterus didelphys with obstructed hemivagina and ipsilateral renal anomaly (OHVIRA SYNDROME): A case report J per Surg Case Reports 2 (2014) 410-412Grimbizis GF, Campo R. Congenital malformations of the female genital tract: The need for a new classification system. Fertil Steril. 2010;94:401-7.
7. Madureria AJ, Maris CM, Bernardes JC, Ramos IM. Uterus didelphys with obstructing hemivagina septum and ipsilateral renal agenesis. Radiol. 2006;239:602-6.

8. Troiano RN, McCarthy SM. Mullerian duct anomalies: imaging and clinical issues. State of the art. Radiol. 2004;233:19-34.

9. Capito C, Echaieb A, Loratat-Jcob S, Thibaud E, Sarnacki S, Nihoul-Fekete C. Pitfalls in the diagnosis and management of obstructive uterovaginal duplication: A series of 32 cases. Pediatr. 2008;122:e891e897.

10. Dhar H, Razek YA, Hamdi I. Uterus Didelphys with obstructed Hemivagina, Ipsilateral Renal Agnesis and Right pyocolpos:a case report. Oman med J. 2011;26(6):447:50.

Cite this article as: Jayanthy T, Rao RB. Ohvira syndrome with left radial hemimelia: a rare association. Int J Reprod Contracept Obstet Gynecol 2021;10:3600-3. 